\title{
Chronic solvent-induced encephalopathy: course and prognostic factors of neuropsychological functioning
}

\author{
Evelien van Valen ${ }^{1,2}$ (D) Ellie Wekking ${ }^{2,3} \cdot$ Moniek van Hout ${ }^{4} \cdot$ Gert van der Laan ${ }^{2,5,6} \cdot$ Gerard Hageman $^{7}$. \\ Frank van Dijk ${ }^{5,8}$. Angela de Boer ${ }^{8} \cdot$ Mirjam Sprangers $^{9}$
}

Received: 13 January 2018 / Accepted: 11 June 2018 / Published online: 25 June 2018

(c) The Author(s) 2018

\begin{abstract}
Purpose Working in conditions with daily exposure to organic solvents for many years can result in a disease known as chronic solvent-induced encephalopathy (CSE). The aims for this study were to describe the neuropsychological course of CSE after first diagnosis and to detect prognostic factors for neuropsychological impairment after diagnosis.

Methods This prospective study follows a Dutch cohort of CSE patients who were first diagnosed between 2001 and 2011 and underwent a second neuropsychological assessment 1.5-2 years later. Cognitive subdomains were assessed and an overall cognitive impairment score was calculated. Paired $t$ tests and multivariate linear regression analyses were performed to describe the neuropsychological course and to obtain prognostic factors for the neuropsychological functioning at follow-up. Results There was a significant improvement on neuropsychological subdomains at follow-up, with effect sizes between small and medium (Cohen's $d 0.27-0.54$ ) and a significant overall improvement of neuropsychological impairment with a medium effect size (Cohen's $d 0.56$ ). Prognostic variables for more neuropsychological impairment at follow-up were a higher level of neuropsychological impairment at diagnosis and having a comorbid diagnosis of a psychiatric disorder at diagnosis. Conclusions Results are in line with previous research on the course of CSE, stating that CSE is a non-progressive disease after cessation of exposure. However, during follow-up the percentage patients with permanent work disability pension increased from 14 to $37 \%$. Preventive action is needed in countries where exposure to organic solvents is still high to prevent new cases of CSE.
\end{abstract}

Keywords Chronic solvent-induced encephalopathy $\cdot$ Follow-up $\cdot$ Course $\cdot$ Prognosis $\cdot$ Neuropsychological assessment $\cdot$ Neurotoxicity · Organic solvents · Diagnostic evaluation

Electronic supplementary material The online version of this article (https://doi.org/10.1007/s00420-018-1328-1) contains supplementary material, which is available to authorized users.

Evelien van Valen

e.vanvalen@umcutrecht.nl

1 Department of Geriatrics, University Medical Center Utrecht, Utrecht, The Netherlands

2 Netherlands Center for Occupational Diseases, Coronel Institute of Occupational Health, Amsterdam Public Health Research Institute, Academic Medical Center, Amsterdam, The Netherlands

3 Mental Health Center Dijk en Duin, Parnassia Groep, Castricum, The Netherlands

4 Department of Medical Psychology, Medisch Spectrum Twente Hospital, Enschede, The Netherlands
5 Foundation Learning and Developing Occupational Health (LDOH), Hilversum, The Netherlands

6 Department of Health Sciences, University of Milano, Milano, Italy

7 Department of Neurology, Medisch Spectrum Twente Hospital, Enschede, The Netherlands

8 Coronel Institute of Occupational Health, Amsterdam Public Health Research Institute, Academic Medical Center, Amsterdam, The Netherlands

9 Medical Psychology, Amsterdam Academic Medical Centers, Amsterdam Public Health Research Institute, Academic Medical Center, Amsterdam, The Netherlands 


\section{Introduction}

Organic solvents may cause harm to the nervous system (White and Proctor 1997) by affecting a range of neuronal processes at different levels: changes in ion channel receptors, cellular responses, tissue responses, changes in brain regions and ultimately in cognitive processes and behaviour (Bushnell et al. 2010; van Thriel 2015; Sainio 2015). People are working with organic solvents in industries such as shoe manufacturing, car repair, industrial or house painting, spray painting, furniture manufacturing, printing and cleaning.

A small subsample of workers who are exposed to organic solvents for a long time-e.g. daily exposure for 5 years or more-have been found to develop a syndrome called chronic solvent-induced encephalopathy (CSE). The severity and duration of the solvent exposure play a role in the development of CSE, but there are also individual variations in the susceptibility to the effects of solvent exposure (Godderis et al. 2010; Kezic et al. 2006). Individual differences exist in toxification and detoxification of solvents in the human body (Sainio 2015).

International diagnostic criteria for this syndrome have been described by the World Health Organization (1985), and subsequently refined by a working group in Raleigh (Baker and Seppäläinen 1986), the European Union (European Commission 2009) and a neuropsychological consensus group (van Valen et al. 2012). CSE is recognized as an occupational disease by the International Labour Organization (2010).

The syndrome of CSE is characterized by symptoms of forgetfulness, concentration problems, fatigue, irritability, mood changes and neuropsychological impairment on measures of speed of information processing, speed of motor performance, and immediate memory (van Valen et al. 2012). SPECT scans and fMRI of CSE patients showed decreased dopaminergic activity in the frontostriatal circuitries (Visser et al. 2008) and electroencephalography showed decreased activity in event-related potentials in the posterior parts of the frontoparietal regions (Keski-Säntti et al. 2012). These neurological measures are only found at group level and do not differentiate across individual cases, they cannot (yet) be used for individual diagnostic evaluation. Therefore the diagnostic assessment of CSE relies on neuropsychological assessment for substantiating the neurotoxic effects of organic solvent exposure.

The results found in CSE patients have also been observed in a population of solvent exposed workers; an fMRI study in solvent exposed workers and non-exposed controls has found lower activity in brain regions of the anterior cingulate cortex, the prefrontal cortex and the parietal cortex (Tang et al. 2011). An earlier review of the neuroimaging data on solvent exposed workers, animal data and case reports of people suffering from solvent abuse has yielded contradicting results and no clear dose-response relationships between solvent exposure and neurological changes could be concluded. The poor quality of several of the studies did not allow for further conclusions (Ridgway et al. 2003).

An effective treatment for neuropsychological impairment constituting CSE does not exist (Åbjörnsson et al. 1998; van Hout et al. 2008). Preventive measures against further deterioration of the disease, such as complete cessation or drastic reduction of the exposure, are often advised.

Studies on the neuropsychological disease course of CSE after first diagnosis indicate that neuropsychological functioning of most patients has stabilized or improved at follow-up (Åbjörnsson et al. 1998; Bruhn et al. 1981; Dryson and Ogden 2000; Edling et al. 1990; Lindström et al. 1982; Morrow et al. 1991; Ørbæk and Lindgren 1988). Prognostic factors for the neuropsychological course have been investigated. For patients with more severe neuropsychological deficits at diagnosis there was more improvement at followup (Dryson and Ogden 2000). Mixed results were found regarding higher age (Lindström et al. 1982; Ørbæk and Lindgren 1988) and a history of peak exposure as negative prognostic factors (Morrow et al. 1991; Ørbæk and Lindgren 1988). Follow-up studies of CSE patients have been critically reviewed by the 'Deutsche Gesetzliche Unfallversicherung' (2007) and van Valen et al. (2009).

These follow-up studies have some limitations. They do not elaborately describe the diagnostic criteria hampering the comparability of the CSE patient groups across studies. The studies employ small sample sizes, ranging from 21 to $86 \mathrm{CSE}$ (type 2 of WHO criteria) patients. Only three studies used multivariate analyses for assessing possible prognostic factors for the neuropsychological course of CSE (Lindström et al. 1982; Morrow et al. 1991; Ørbæk and Lindgren 1988). None of the studies checked for possible problems with performance validity (also called insufficient effort/ malingering/non-credible performance) or involvement in litigation. Standardized psychiatric evaluations for comorbid psychopathology were not used. The mean follow-up time varied across studies, ranging from 1.3 to 7 years (van Valen et al. 2009).

The main objectives of this study are to examine the course of the disease and the prognostic factors of neuropsychological functioning of CSE patients, taking these shortcomings into account. The following questions are addressed: (1) what is the course of neuropsychological and psychiatric functioning, and psychological symptoms of CSE patients over time? (2) Which prognostic variables predict the neuropsychological functioning of CSE patients at follow-up? Results of this study can be used to inform patients and other stakeholders about the course of CSE and the prognostic factor(s) that may be subject of intervention in individual patients. 


\section{Methods}

\section{Study design and setting}

This prospective study follows a cohort of CSE patients from the Dutch hospitals Academic Medical Center Amsterdam and Medical Spectrum Twente Enschede who are first diagnosed between 2001 and 2011 and have a second neuropsychological assessment 1.5-2 years later. The follow-up assessment of the last patient in this study took place in April 2014.

Clinical data are anonymized. As this study concerns care as usual, no extra interventions or medical and psychological assessments are conducted and no special research approval was needed. Therefore, a dispensation decision for this study was obtained from the Medical Ethics Committee of the Academic Medical Center Amsterdam. The patient care and data handling are according to guidelines of the Dutch

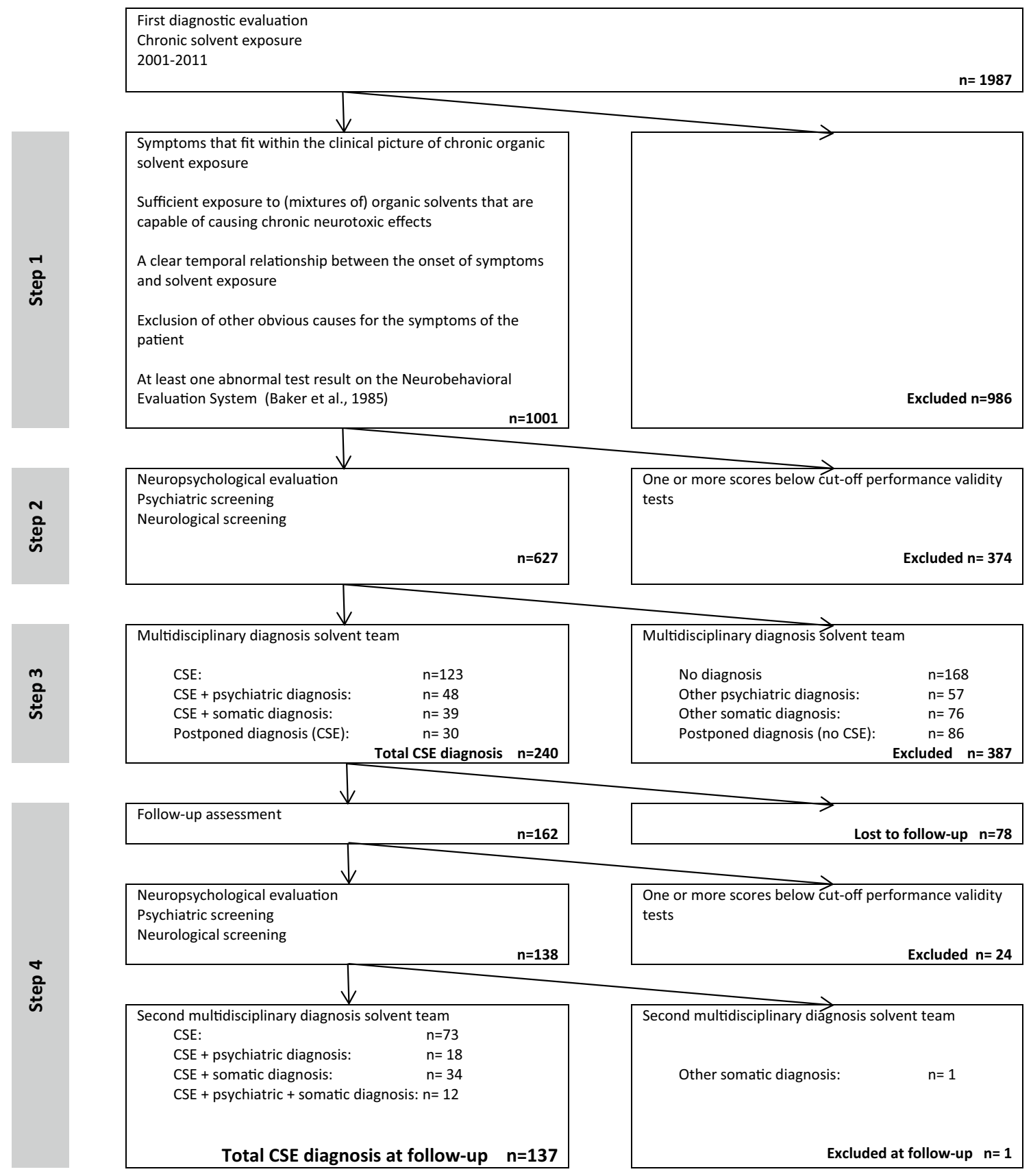

Fig. 1 Flow chart referrals Solvent Teams 2001-2011 to patient group selection follow-up 
legislation, declaration of Helsinki and the local guidelines of the Academic Medical Center and Medical Spectrum Twente.

\section{Diagnostic procedure}

In the Netherlands, there are two specialized centres for the assessment of cases of chronic solvent-induced encephalopathy. These multidisciplinary centres are called Solvent Teams and consist of an occupational physician, occupational hygienist, clinical neuropsychologist, and neurologist. If necessary, a toxicologist, psychiatrist or other medical specialist is consulted. The diagnostic protocol of the Solvent Teams (van der Laan et al. 1995; van Valen et al. 2015) uses a stepwise approach to assess the international consensus-based criteria for CSE (WHO 1985; Baker and Seppäläinen 1986; European Commission 2009; van Valen et al. 2012). The diagnostic steps are represented in the flow chart of Fig. 1.

\section{Participants}

Patients are eligible for inclusion when they are referred to the Dutch Solvent Teams for a first diagnostic evaluation for occupational chronic solvent exposure-related health complaints. Patients who complete the whole diagnostic process and are diagnosed having CSE, are invited for a follow-up assessment. The CSE patients who are re-assessed and still meet the criteria for CSE constitute the patient group of this study.

The included CSE patients are diagnosed according to the diagnostic criteria Type 2 of the WHO (WHO 1985) and Type 2B of the Raleigh criteria (Baker and Seppäläinen 1986), which means that five diagnostic criteria are met: (1) the symptoms fit within the clinical picture of chronic organic solvent exposure. (2) There is exposure for at least 5 years to (mixtures of) organic solvents that are capable of causing chronic neurotoxic effects. (3) There is a clear temporal relationship between the onset of symptoms and solvent exposure. (4) Other major somatic or psychiatric causes for the symptoms of the patient are ruled out. (5) Neuropsychological assessment shows impairments that fit within the cognitive profile of CSE. We added a sixth criterion, because suboptimal performance on neuropsychological assessment is highly prevalent in this patient group (van Hout et al. 2003) and this decreases the diagnostic validity of the neuropsychological assessment. (6) Performance validity of the neuropsychological tests are above cut-off ( 44 on the third booklet of Test of Memory Malingering, (TOMM, Tombaugh 1996) and 80 on the Amsterdam Short-Term Memory test, (ASTM, Schmand et al. 1999), indicating no problems with mental effort, suboptimal performance or malingering on the neuropsychological assessment.

\section{Variables}

Outcome variables Neuropsychological functioning Neuropsychological functioning is the main outcome of this study. Neuropsychological functioning is composed of the neuropsychological domains memory, attention, motor function and intellectual function. Within the neuropsychological domains, subdomains are configured according to European neuropsychological consensus (van Valen et al. 2012) and included tests are listed in Table 1. Raw scores from the neuropsychological tests at diagnosis and followup assessment are compared to normative data of the test manual or in some tests national available updates of the normative data (Schmand et al. 2012) (see Table 1) and are converted to $z$ scores.

Neuropsychological compound scores subdomains For the description of the course of neuropsychological functioning, there is a need for data-reduction. The 28 test variables will be reduced to nine compound scores that cover four neuropsychological domains: memory (immediate recall, delayed recall and recognition), attention (simple attention and complex attention), motor function (motor speed and dexterity) and intellectual functioning (verbal intelligence and visuoconstruction). In Table 1 the tests are listed. The compound scores are calculated by averaging the $z$ scores within the subdomains. For each subdomain there should be at least two test variables available to calculate a compound score. If two or more test variables of the same test are present within a subdomain (e.g. pegboard dominant hand and pegboard non-dominant hand), they are counted as one score by averaging the $z$ scores of the different variables of the specific test.

Neuropsychological impairment score A single measure for neuropsychological impairment at diagnosis and followup is obtained. The $z$ scores of the 28 neuropsychological test variables are aggregated into a total neuropsychological impairment score by summing the number of test scores below $-1.65 z$. In case of missing data, a test score is considered as not impaired. The total neuropsychological impairment score ranges between 0 (no neuropsychological impairment) to 28 (impairment indicated by all test variables of neuropsychological assessment).

Psychiatric functioning Psychiatric functioning was measured with a semi-structured clinical interview assessing the axis I disorders of the DSM-IV using the SCID-I (van Groenestijn et al. 1999; First et al. 1996). For each psychiatric diagnostic category of the SCID-I, a dichotomized score is obtained: 0 -no diagnosis and $1-$ criteria for psychiatric disorder are met. A dichotomized score for overall axis I psychopathology is used with 0 indicating no psychopathology and 1, one or more psychiatric axis I disorders according to DSM-IV criteria. 
Table 1 Tests of neuropsychological assessment Solvent Team

\begin{tabular}{|c|c|c|c|c|c|}
\hline \multirow[t]{2}{*}{ Domain } & \multirow{2}{*}{$\begin{array}{l}\text { Subdomain } \\
\text { Test }\end{array}$} & \multicolumn{3}{|c|}{ Adjustment norm data } & \multirow[t]{2}{*}{ Test/norm reference } \\
\hline & & Age & Gender & Education & \\
\hline \multirow[t]{13}{*}{ Memory } & Immediate recall & & & & \\
\hline & NES2 digit span forward & + & + & + & Baker and Letz (1985) \\
\hline & NES2 digit span backward NES2 & + & + & + & Baker et al. (1985) \\
\hline & Dutch California Verbal Learning Test, total list & + & + & - & Mulder et al. (1996) \\
\hline & Rivermead stories, immediate recall & + & + & + & Schmand et al. (2012) \\
\hline & Wechsler memory scale-revised, immediate recall & + & - & - & Wechsler (1987) \\
\hline & Delayed recall & & & & \\
\hline & Dutch California Verbal Learning Test, consolidation & + & + & - & Mulder et al. (1996) \\
\hline & Rivermead stories, delayed recall & + & + & + & Schmand et al. (2012) \\
\hline & Wechsler memory scale-revised, delayed recall & + & - & - & Wechsler (1987) \\
\hline & Recognition & & & & \\
\hline & Dutch California Verbal Learning Test, recognition & + & + & - & Mulder et al. (1996) \\
\hline & Recognition memory test, faces & + & - & - & Warrington (1984) \\
\hline \multirow[t]{9}{*}{ Attention } & Simple attention & & & & \\
\hline & NES2 symbol-digit substitution & + & + & + & Baker et al. (1985) \\
\hline & Trail Making Test, form A & + & - & + & Schmand et al. (2012) \\
\hline & Stroop test words & + & + & + & Schmand et al. (2012) \\
\hline & Stroop test colours & + & + & + & Schmand et al. (2012) \\
\hline & Complex attention & & & & \\
\hline & NES2 colour-word vigilance & + & + & + & Baker et al. (1985) \\
\hline & Trail Making Test, form B (relative to A) & + & - & + & Schmand et al. (2012) \\
\hline & Stroop test colour-word, interference & + & + & + & Schmand et al. (2012) \\
\hline \multirow[t]{8}{*}{ Motor function } & Motor speed & & & & \\
\hline & NES2 simple reaction time & + & + & - & Baker et al. (1985) \\
\hline & NES2 finger tapping dominant hand & + & + & + & Baker et al. (1985) \\
\hline & NES2 finger tapping non-dominant hand & + & + & + & Baker et al. (1985) \\
\hline & Dexterity & & & & \\
\hline & NES2 hand-eye coordination & + & + & + & Baker et al. (1985) \\
\hline & Grooved pegboard, dominant hand & + & - & - & Heaton et al. (1986) \\
\hline & Grooved pegboard, non-dominant hand & + & - & - & Heaton et al. (1986) \\
\hline \multirow[t]{7}{*}{ Intellectual function } & Verbal function & & & & \\
\hline & Verbal fluency animals & + & + & + & Schmand et al. (2012) \\
\hline & Verbal fluency occupations & + & + & + & Schmand et al. (2012) \\
\hline & WAIS-III similarities & + & + & - & Wechsler $(2001,2004)$ \\
\hline & Visuoconstruction & & & & \\
\hline & WAIS-R/WAIS-III block design & + & + & - & Wechsler $(1981,2001,2004)$ \\
\hline & Rey complex figure test copy & + & - & - & Visser (1970) \\
\hline
\end{tabular}

In case of a psychiatric diagnosis on the SCID-I in the domain of mood or anxiety disorders, a clinician-rated measure of the severity of the psychiatric impairment is obtained using the Hamilton rating Scale for Depression (HRSD) (Hamilton 1960) or Hamilton Anxiety Rating Scale (HARS) (Hamilton 1959). The HRSD consists of 21 items, of which 17 contribute to the total score. Eight items have a scale ranging from 0 (absent) to 4 (severe), 9 items have a scale ranging from 0 (absent) to 2 (obviously present). The total score ranges from 0 to 52 with $0-7$ labelled as no depression, 8-13 as mild, 14-18 mild to moderate, 19-27 moderate to severe and $>28$ severe. The HARS consists of 14 items which are scored on a scale ranging from 0 (absent) to 4 (severe). The total score ranges from 0 to 56 , with $0-17$ labelled as mild, 18-24 as mild to moderate, 25-30 moderate to severe and $>30$ severe anxiety problems.

Psychological symptoms The severity of psychological symptoms is measured with the Symptom Check List (SCL-90), which includes 90 items that are combined to form 9 subscales and a total psychological symptoms score. 
A 1-5 response scale is employed with the total score ranging between 90 and 450. Normative data of different patient groups and the general population of the Netherlands are available (Derogatis 1975; Ettema and Arrindell 2003).

Predictors Age Age is measured in years at time of the first neuropsychological assessment (diagnosis) and at time of the follow-up assessment.

Education For education the Dutch Verhage score is used, with seven categories: ranging from unfinished primary school to university degree (Verhage 1964).

Exposure Cumulative exposure is estimated in retrospect with the formula described in the "Appendix". The exposure estimation is based on the information obtained from the patient, in combination with the knowledge on solvent use in diverse sectors at different times in the Netherlands (Fransman et al. 2002). In the rare case of the availability of air monitoring measurements or biomonitoring data, these are also incorporated in the estimation of the cumulative exposure. The range of the cumulative exposure estimation is between 0 for no exposure up to more than 400 in extreme cases. The number of years of working while exposed is recorded. This is a variable not including the weighing of the severity of the exposure. This measure is used for comparability purposes with other studies.

The number of months since the last exposure is listed. And a variable is computed whether exposure has ceased, diminished or is still ongoing at time of diagnosis and follow-up.

Somatic comorbidity The presence of somatic diseases is enquired during the interview, retrieved from medical files or diagnosed by the neurologist and the occupational physician. A total score for somatic diseases with partly similar symptoms as CSE is obtained by summing the following conditions: cardiac problems, hypertension or hypotension, diabetes, hypothyroidism, neurological disease (including sleep disorders and polyneuropathies), migraine, and respiratory problems (including asthma and allergies). The total score is dichotomized into 0 : no somatic comorbidity and 1 : at least one somatic comorbidity.

Alcohol Use of alcohol is measured in units of alcoholic drinks per week. The amount of alcoholic consumptions is recalculated to "standard glasses" in which 1 unit represents a maximum of $12 \mathrm{ml}$ or $10 \mathrm{~g}$ of alcohol within the drink (for example, 1 unit is a beer of $250 \mathrm{ml}, 1.3$ units represents a bottle of beer, 1 unit of strong liquor is $35 \mathrm{ml}$, and 1 unit of wine is $100 \mathrm{ml}$ ).

Use of psychotropic medication Use of psychotropic medication is dichotomized into 0 , no psychotropic medication versus 1 , use of psychotropic medication (e.g. selective serotonin reuptake inhibitors, selective noradrenaline reuptake inhibitors, tricyclic antidepressants, benzodiazepines, antipsychotics, anti-epileptics and opioid painkillers).
Work situation Whether a patient still works in his or her occupation is recorded. We distinguish different categories of work situation: currently working in the same job where most of the exposure was obtained; currently working but in another job than where most of the exposure was obtained; on sick leave for at least 2 weeks; not working but receiving disability pension, retirement or unemployment. For the analysis the variable is dichotomized into: currently working (1) and not-working (0).

Litigation Involvement in litigation process is dichotomized as $0-$ no involvement and 1 -involvement, such as legal procedures against former employer or procedures against social security agencies or private insurance companies.

Background variables Occupation Occupation is operationalized as the occupation related to exposure to solvents, with the following classes of occupations: painters, spraypainters, printers, chemical workers or people working in the paint industry, floor layers, upholsterers and other occupations (e.g. shipyard workers and shoe factory workers).

Follow-up time Follow-up time is measured in number of months between the first and the second neuropsychological assessment.

\section{Statistical analysis}

To describe possible selection bias, the study group is compared to the 'lost to follow-up' group and the 'group with below cut-off performance validity on the follow-up assessment' on demographic characteristics, neuropsychological and psychiatric functioning at first diagnostic assessment, using oneway ANOVA and post hoc tests (LSD correction) or Kruskal-Wallis tests for non-parametric variables.

The course of neuropsychological and psychiatric functioning and psychological symptoms over time is tested with paired $t$ tests or for non-parametric variables, with the $\chi^{2}$ test. Cohen's $d \mathrm{~s}$ are calculated for the effect size of the paired $t$ tests (an effect size is labelled small if $d: 0.2$, medium if $d$ : 0.5 and large if $d: 0.8$ or higher).

For the identification of possible prognostic factors a linear regression analysis is performed, with the total neuropsychological impairment score at follow-up as the dependent variable.

Possible prognostic factors at diagnosis include neuropsychological impairment at first diagnostic assessment, psychiatric functioning, psychological symptoms, age, education, cumulative exposure index, a history of peak exposure, somatic comorbidity, units of alcohol per week, use of psychotropic medication, working situation and involvement in litigation. All prognostic factors are evaluated with univariate analyses. Only factors with $p<0.20$ are selected for the multivariate linear regression. Subsequently, a check 
for multicollinearity is performed using scores of variance inflation factors and in case of positive results the collinear factor is excluded.

\section{Results}

\section{Participants}

From 2001 to 2011, 1,987 patients have been referred to the Solvent Teams for a first diagnostic evaluation for chronic solvent exposure-related health complaints. Most patients were referred by general practitioners $(51 \%)$, followed by referrals by occupational physicians $(22 \%)$, neurologists $(11 \%)$ and other medical specialists (16\%). At the time of the first diagnostic step most patients were still working (47\%) or on short-term sick leave (22\%). Others received disability pension $(21 \%)$, were unemployed $(6 \%)$ or retired $(4 \%)$.

The inclusion flow chart is presented in Fig. 1. 1,001 patients met the inclusion criteria 1-4 of the WHO. Of these, 627 patients showed sufficient performance validity on the TOMM and ASTM and could proceed in the diagnostic procedure. $37 \%$ of the patients from step 1 were excluded in step 2 due to insufficient performance validity. The multidisciplinary team subsequently identified 240 patients with a CSE diagnosis or a combined differential diagnosis with CSE.

After first diagnosis, 78 CSE patients were lost to followup. The most common reasons were: the long traveling distance to one of the Solvent Teams, the effort and energy it would take to undergo a neuropsychological assessment, the wish to end the sometimes difficult diagnostic process and diagnosis, the wish to avoid the confrontation with one's disabilities, and the possible negative impact of a new diagnostic evaluation on the status of one's disability pension or other kind of financial compensation.

The 'lost to follow-up' group $(n=78)$ and the patients who were excluded at follow-up due to insufficient performance validity $(n=24)$ did not differ from the study group with respect to age $(F(2,236)=0.79, p=0.46)$, education $(F(2,236)=2.53, p=0.08)$ and work situation $\left(\chi^{2}(2\right.$, $N=235)=0.37, p=0.83)$. However, significant differences were found between groups with respect to involvement in a litigation procedure $\left(\chi^{2}(2, N=238)=7.74, p=0.02\right)$ with percentages of patients involved in a litigation procedure ranging from $15 \%$ in the study group to $29 \%$ in the lost to follow-up group and $38 \%$ in the insufficient performance validity group. At time of first diagnosis, no significant differences were found on number of impaired tests at neuropsychological assessment between the study group, the lost to follow-up group and the decreased performance validity at follow-up group $(F(2,235)=0.72, p=0.49)$. The groups also did not differ with regard to the severity of psychological symptoms $(F(2,232)=0.05, p=0.95)$.

\section{Descriptive data}

The characteristics of the study participants are listed in Table 2 . There are only 3 (2\%) women in the study group. At time of first diagnosis most of the participants are in their 40 s and 50 s (80\%) and most have a history of more than 15 years of daily solvent exposure (83\%). More than half of the patients have ceased or lowered exposure prior to the first diagnostic assessment. Most of the study participants are blue collar workers with lower occupational education (71\%). At time of follow-up the majority of patients is not exposed to solvents anymore (75\%). Also, at time of followup many patients have a different working situation. The percentage of patients needing some sort of social security (sick leave or long-term disability pension) had increased from 43 to 55\%. Among these, the percentage patients with a permanent work disability pension increased noticeably from 14 to $37 \%$. The somatic comorbidity at diagnosis and follow-up is listed in Table 3.

\section{Course of neuropsychological functioning}

For each test variable a percentage of impaired tests results at group level is given reflecting the percentage of tests scores below $-1.65 z$, see Table 4 . The most impaired test results are found in the subdomains immediate recall of memory, simple and complex attention and motor speed. In the domain of intellectual functioning few patients had impaired test results; $1-17 \%$ impairments.

Paired sample $t$ tests of the mean $z$ scores showed significant improvement at follow-up on 6 of the 9 subdomains. The size of the improvement at group level ranges between 0.1 and $0.3 z$ scores.

The mean neuropsychological impairment of patients at diagnosis (7.2, sd 3.3) and at follow-up (5.5, sd 3.3), decreased significantly $(t(136)=6.5, p=0.000)$ with a medium effect size of Cohen's $d 0.56$.

\section{Course of psychiatric functioning and psychological symptoms}

In Table 5, psychiatric diagnoses and corresponding mean Hamilton mood and anxiety severity ratings are given. The semi-structured psychiatric interview was found to be indicative of a DSM-IV psychiatric axis I disorder in 49 of the 137 included patients at time of diagnosis. At followup, the number of patients with psychiatric axis I diagnoses decreased to $30\left(\chi^{2}(1, N=137)=19.6, p=0.000\right)$.

The total score of the psychological symptoms of the study group have significantly decreased at follow-up; from a mean total score at diagnosis of $185(\mathrm{sd}=57)$ to a mean total score of $173(\mathrm{sd}=51) ; t(134)=3.6, p=0.000$ with a small effect size of Cohen's $d 0.31$. The mean level of 
Table 2 Demographic data $(n=137)$

\begin{tabular}{|c|c|c|c|c|}
\hline & \multicolumn{2}{|c|}{ At diagnosis } & \multicolumn{2}{|c|}{ At follow-up } \\
\hline & Frequency & $\%$ & Frequency & $\%$ \\
\hline \multicolumn{5}{|l|}{ Gender } \\
\hline Male & 134 & 98 & - & - \\
\hline Female & 3 & 2 & - & - \\
\hline \multicolumn{5}{|l|}{ Age } \\
\hline$<30$ years & 3 & 2 & 3 & 2 \\
\hline $31-40$ years & 20 & 15 & 12 & 9 \\
\hline $41-50$ years & 53 & 38 & 51 & 37 \\
\hline $51-60$ years & 58 & 42 & 63 & 46 \\
\hline $61-70$ years & 3 & 2 & 8 & 6 \\
\hline \multicolumn{5}{|l|}{ Education } \\
\hline Primary education & 7 & 5 & - & - \\
\hline Lower occupational (no diploma) & 17 & 13 & - & - \\
\hline Lower occupational (diploma) & 73 & 53 & - & - \\
\hline Mid-level & 37 & 27 & - & - \\
\hline College and above & 3 & 2 & - & - \\
\hline \multicolumn{5}{|l|}{ Exposure level } \\
\hline Low (cumulative index $<15$ ) & 9 & 6 & - & - \\
\hline Intermediate (cumulative index 15-49) & 33 & 25 & - & - \\
\hline High (cumulative index $\geq 50$ ) & 95 & 69 & - & - \\
\hline \multicolumn{5}{|l|}{ Exposure years } \\
\hline $0-5$ years & 0 & 0 & - & - \\
\hline $6-15$ years & 23 & 17 & - & - \\
\hline $16-20$ years & 27 & 19 & - & - \\
\hline$>20$ years & 87 & 64 & - & - \\
\hline \multicolumn{5}{|l|}{ Current exposure } \\
\hline Ongoing exposure & 35 & 25 & 10 & 7 \\
\hline Exposure decreased & 30 & 22 & 25 & 18 \\
\hline Cessation of exposure & 72 & 53 & 103 & 75 \\
\hline \multicolumn{5}{|l|}{ Occupation } \\
\hline Painters & 47 & 35 & - & - \\
\hline Spray-painters & 39 & 28 & - & - \\
\hline Printers & 19 & 14 & - & - \\
\hline Chemical/paint industry & 5 & 4 & - & - \\
\hline Floor layers & 3 & 2 & - & - \\
\hline Upholsterers & 8 & 6 & - & - \\
\hline Other & 16 & 11 & - & - \\
\hline \multicolumn{5}{|l|}{ Work situation } \\
\hline Working, same job & 65 & 48 & 28 & 20 \\
\hline Working, other job & 12 & 9 & 34 & 25 \\
\hline Sick leave & 35 & 25 & 14 & 10 \\
\hline Disability pension & 20 & 14 & 50 & 37 \\
\hline Retired & 1 & 1 & 4 & 3 \\
\hline Unemployed/welfare & 4 & 3 & 7 & 5 \\
\hline \multicolumn{5}{|l|}{ Litigation } \\
\hline Yes & 20 & 15 & - & - \\
\hline No & 117 & 85 & - & - \\
\hline \multicolumn{5}{|l|}{ Alcohol use } \\
\hline No alcohol & 48 & 35 & 46 & 33 \\
\hline $1-7$ per week & 51 & 38 & 63 & 46 \\
\hline
\end{tabular}


Table 2 (continued)

\begin{tabular}{|c|c|c|c|c|}
\hline & \multicolumn{2}{|c|}{ At diagnosis } & \multicolumn{2}{|c|}{ At follow-up } \\
\hline & Frequency & $\%$ & Frequency & $\%$ \\
\hline $8-14$ per week & 18 & 13 & 15 & 11 \\
\hline 15-28 per week & 14 & 10 & 9 & 7 \\
\hline$>28$ per week & 6 & 4 & 4 & 3 \\
\hline \multicolumn{5}{|l|}{ Solvent Team diagnosis } \\
\hline CSE & 65 & 47 & 73 & 53 \\
\hline CSE and psychiatric diagnosis & 32 & 22 & 18 & 13 \\
\hline CSE and somatic diagnosis & 24 & 18 & 34 & 25 \\
\hline CSE and psychiatric and somatic diagnosis & 18 & 13 & 12 & 9 \\
\hline \multicolumn{5}{|c|}{ Time between first diagnosis and follow-up assessment } \\
\hline \multirow[t]{2}{*}{ Mean number of months (sd; median) } & & & 21 & $(14 ; 21)$ \\
\hline & & & (Min 6 & Max 88) \\
\hline
\end{tabular}

- Means no change from diagnosis to follow-up

Table 3 Somatic comorbidity

\begin{tabular}{lll}
\hline & At diagnosis & At follow-up \\
& $n$ & $n$ \\
\hline Total somatic diseases & $42(30 \%)$ & $46(34 \%)$ \\
Cardiac problems & 8 & 10 \\
Hypertension & 16 & 16 \\
Hypotension & 4 & 2 \\
Diabetes type 2 & 11 & 12 \\
Hypothyroidism & 3 & 3 \\
Neurological diseases & 7 & 7 \\
Migraine & 6 & 7 \\
Respiratory problems & 12 & 14 \\
\hline
\end{tabular}

psychological symptoms would be labelled by the normative data of the SCL-90 as very high at first diagnosis and high at follow-up in comparison with a norm group of age and gender matched general population (Ettema and Arrindell 2003).

\section{Prognostic variables at diagnosis for neuropsychological impairment at follow-up}

Univariate linear regression analyses identified six possible prognostic factors measured at time of diagnosis for inclusion in the multivariate regression model for the neuropsychological impairment at follow-up: neuropsychological impairment, psychiatric functioning, psychological symptoms, education, weekly alcohol intake and the use of psychotropic medication, see Table 6 . There was no indication of multicollinearity. A statistically significant multivariate linear regression model was obtained $(F(6,130)=14.89$, $p<0.000$ ) with a $R^{2}$ of 0.407 . Severity of neuropsychological impairment and psychiatric functioning (a comorbid axis I psychiatric disorder) at diagnosis remained significant predictive factors for a relatively high level of neuropsychological impairment at follow-up.

\section{Discussion}

The current study aims to contribute to the understanding of the (neuro)psychological course and predictors of CSE by studying a cohort of CSE patients over an average of 21 months after their first diagnosis, in the Netherlands. The neuropsychological impairment in CSE patients was found to decrease over time, although the magnitude of the reduction was medium to small. The psychological symptoms have improved over time and fewer patients meet the DSM-IV criteria for psychopathology (a decrease from 36 to $22 \%$ ). At time of follow-up however, neuropsychological impairment and psychological problems still exist. The percentage patients with a work disability pension increased noticeably during follow-up.

Neuropsychological impairment at diagnosis was found to predict the level of neuropsychological impairment at follow-up. Moreover, a psychiatric DSM-IV diagnosis at time of CSE diagnosis was also found to predict neuropsychological impairment at follow-up.

These results are in line with previous research on the course of CSE, stating that CSE is a non-progressive disease with no severe deterioration after cessation of exposure (van Valen et al. 2009).

Cumulative exposure to organic solvents and peak exposure did not predict the course of the neuropsychological functioning of CSE patients. This contradicts an earlier study which has found peak exposure as a predictor of the neuropsychological course (Morrow et al. 1991) although Ørbæk and Lindgren (1988) also did not find a significant effect of exposure on the neuropsychological 


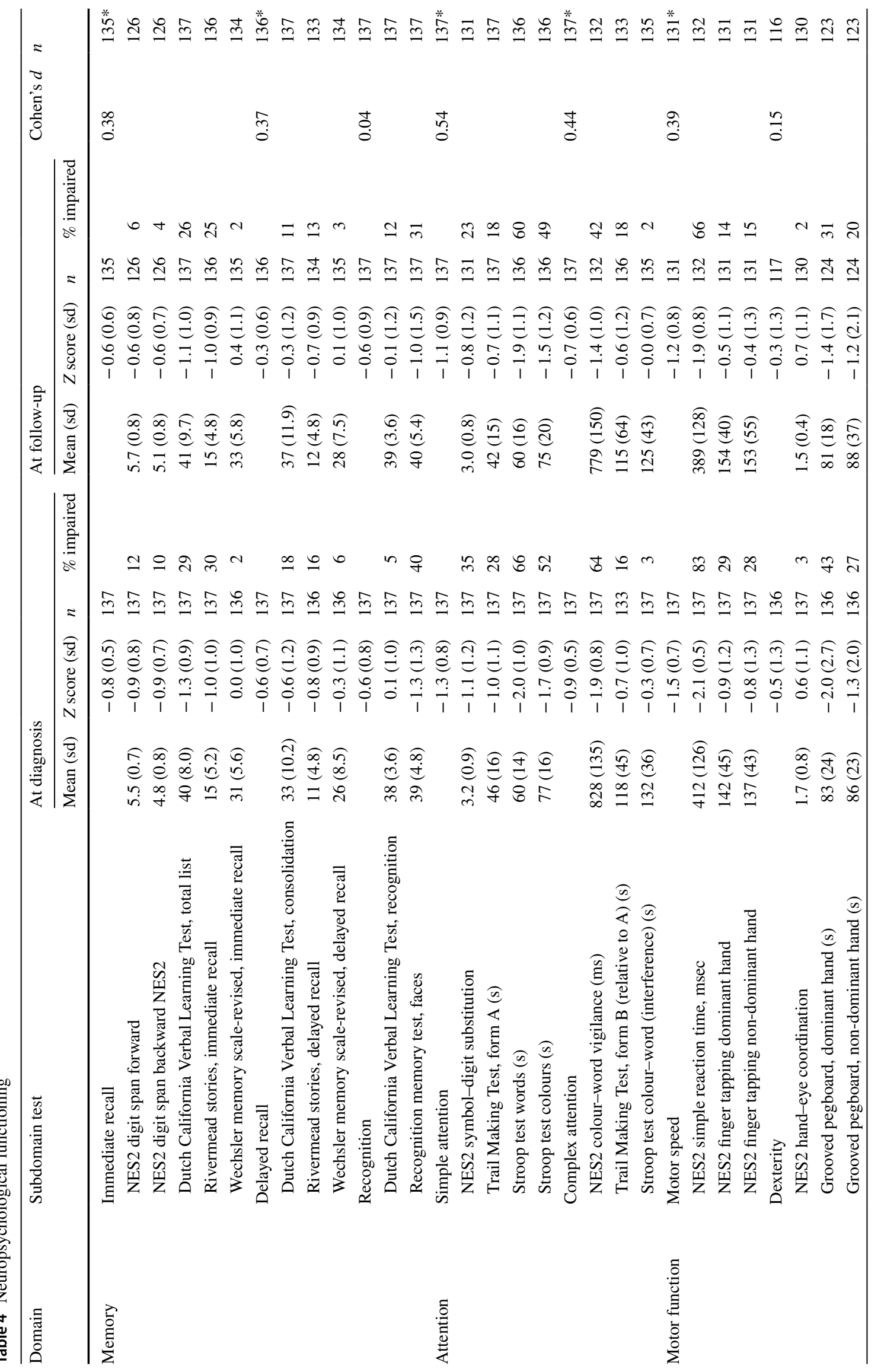


test performance at follow-up in a prognostic study. In the current study, there is no evidence for a dose-response relationship between exposure and the course of the neuropsychological functioning in CSE patients. The design of a longitudinal follow-up study on the heavily selected patient population of diagnosed CSE patients is not adequate to obtain knowledge about dose-response relationships. An inclusion criterion for a CSE diagnosis is a cumulative exposure high enough to be able to cause CSE. The patients in this study therefore all have sufficient exposure to be able to cause adverse health effects. As a consequence, the majority of the patients in this study only do vary in range of cumulative exposure between intermediate and high, only $6 \%$ of the patients has a low exposure corresponding with at least 6 years of solvent exposure and a maximum of 44 years. For evidence for (the absence of) a dose-response relationship there is a need for cohort studies in the original population of workers in which the solvent-exposed workers are compared to a well-chosen population of workers with no exposure. Another reason to be very cautious using a prognostic design for etiological conclusions is that the course of an occupational disease after diagnosis may not be influenced by the previous exposure.

The long-term effects of chronic solvent exposure in workers after cessation of exposure have also been described in epidemiological cohort studies and follow-up studies of exposed workers and unexposed controls. These point in the direction of a high lifetime exposure to organic solvents causing more psychological problems and an exacerbation of age-related cognitive impairment (Dick et al. 2010; Nordling Nilson et al. 2002, 2003, 2007, 2010; Sabbath et al. 2014). The results are in agreement with the hypothesis that exposure to organic solvents in working life decreases the cognitive reserve capacity (Stern 2002) and thereby causes an acceleration of the normal aging process, even many years after exposure has ceased. In our study we did not find such aging processes progressing over time. To the contrary, instead of deterioration we found an improvement of neuropsychological functioning over 2 years. We do not know whether the cognitive aging effects as found in epidemiological studies would be found in our CSE patients when the follow-up time would be longer, at least 10 years. However, a matched control group is needed for this kind of study to distinguish between effects of 'pure' aging and late effects of solvent exposure.

Leaving the exposure to solvents as a causal explanation for the neuropsychological impairment of CSE-patients out of consideration, one could state that the CSE-patients identified at first diagnosis are in fact patients with nonamnestic mild cognitive impairment (MCI) (Petersen 2016; Gerstenecker and Mast 2014). Mild cognitive impairment is found in the aging population. Patients show no signs (yet) of interference in activities of daily life, but do have mild 
Table 5 Psychiatric functioning

\begin{tabular}{|c|c|c|c|c|}
\hline \multirow{3}{*}{ Psychiatric axis I disorders } & \multicolumn{2}{|c|}{ At diagnosis } & \multicolumn{2}{|c|}{ At follow-up } \\
\hline & \multicolumn{2}{|l|}{$n$} & \multicolumn{2}{|l|}{$n$} \\
\hline & 49 & $(36 \%)$ & 30 & $(22 \%)$ \\
\hline & & Mean Hamilton Depression (sd) & & Mean Hamilton Depression (sd) \\
\hline Mood disorders+ & 39 & $18.2(6.1)$ & $19^{*}$ & $20.0(3.3)$ \\
\hline Major depression & 28 & & 15 & \\
\hline Dysthymia & 6 & & 3 & \\
\hline Depression NOS & 5 & & 1 & \\
\hline Bipolar depression & 0 & & 0 & \\
\hline \multirow[t]{2}{*}{ Psychosis } & 0 & & 0 & \\
\hline & & Mean Hamilton Anxiety (sd) & & Mean Hamilton Anxiety (sd) \\
\hline Anxiety disorders ++ & 24 & $17.2(6.6)$ & $19^{*}$ & $18.7(7.2)$ \\
\hline Agoraphobia & 3 & & 0 & \\
\hline Panic disorder & 4 & & 7 & \\
\hline Panic disorder with agoraphobia & 2 & & 2 & \\
\hline Social phobia & 8 & & 5 & \\
\hline Specific phobia & 1 & & 1 & \\
\hline Generalized anxiety disorder & 8 & & 6 & \\
\hline Post-traumatic stress disorder & 0 & & 0 & \\
\hline Hypochondria & 0 & & 0 & \\
\hline Obsessive compulsive disorder & 1 & & 0 & \\
\hline Substance abuse & 13 & & 13 & \\
\hline Alcohol abuse lifetime & 11 & & 11 & \\
\hline Alcohol addiction lifetime & 2 & & 2 & \\
\hline Drug abuse lifetime & 3 & & 3 & \\
\hline Drug addiction lifetime & 0 & & 0 & \\
\hline Drug abuse current & 0 & & 0 & \\
\hline Current abstinence from alcohol & 3 & & 2 & \\
\hline Current alcohol use & 10 & 12.3 per week $(16.7)$ & 11 & 8.1 per week $(10.0)$ \\
\hline \multicolumn{5}{|l|}{ Other psychiatric disorders } \\
\hline Somatic disorder & 0 & & 0 & \\
\hline Somatoform disorder & 0 & & 0 & \\
\hline Pain disorder & 1 & & 0 & \\
\hline Eating disorder & 0 & & 0 & \\
\hline
\end{tabular}

*Chi-square tests of number of mood and anxiety disorders at follow-up $p<0.05$

cognitive impairment at neuropsychological assessment. These MCI-patients mimic the neuropsychological profile of CSE-patients evaluated at one measurement in time. However, the disease course of MCI differs from CSE. Although two meta-analyses found evidence for a reversion of neuropsychological deficits in 18-24\% of MCI-patients (Canevelli et al. 2016; Malek-Ahmadi 2016), most studies found an increase of neuropsychological impairment and a progression from MCI to dementia with prevalences depending on the subtype of MCI (Amieva et al. 2004; Petersen 2016; Aerts et al. 2017). Patients with MCI who are assessed with a number of the same neuropsychological tests and compared to the same normative data as the CSE patients in this study, show comparable sizes of neuropsychological impairment at first diagnosis (Schmand et al. 2014), although it must be noted that this MCI study group is older than our CSEpatient group. After 2 years, the MCI-group shows a mean deterioration of $0.6 \mathrm{sd}$, which differs from our finding of an overall improvement in neuropsychological functioning of CSE patients. Also, within 2 years $23 \%$ of their entire study group and $41 \%$ of the patients diagnosed with MCI at first diagnostic evaluation progresses into dementia, compared with none of the CSE-patients in our study group progressed into dementia within the short follow-up period. In conclusion: the neuropsychological course of CSE differs from the course of MCI and indicates other underlying aetiology.

This is the first follow-up study of CSE-patients that included a classification of psychiatric disorders according 
Table 6 Prognostic factors for level of neuropsychological impairment at follow-up

\begin{tabular}{|c|c|c|c|c|}
\hline \multirow[t]{2}{*}{ Variables measured at diagnosis } & \multicolumn{2}{|c|}{ Univariate } & \multicolumn{2}{|c|}{ Multivariate } \\
\hline & $B$ & Sig. & $B$ & Sig. \\
\hline (Constant) & & & 3.933 & 0.011 \\
\hline Neuropsychological impairment & 0.593 & 0.000 & 0.558 & 0.000 \\
\hline Psychiatric functioning & 1.301 & 0.025 & 1.083 & 0.041 \\
\hline Psychological symptoms & 0.011 & 0.022 & -0.004 & 0.390 \\
\hline Age & 0.015 & 0.662 & & \\
\hline Education & -0.968 & 0.003 & -0.476 & 0.080 \\
\hline Cumulative exposure & 0.003 & 0.464 & & \\
\hline History of peak exposure & 0.109 & 0.898 & & \\
\hline Somatic comorbidity & -0.668 & 0.270 & & \\
\hline Weekly alcohol intake & -0.061 & 0.047 & -0.032 & 0.185 \\
\hline Use of psychotropic medication & 0.968 & 0.120 & 0.280 & 0.586 \\
\hline Work situation & -0.663 & 0.239 & & \\
\hline Involvement in litigation & 0.184 & 0.813 & & \\
\hline
\end{tabular}

to DSM-IV criteria. When looking at the similar level of psychological symptoms in the previous follow-up studies, it seems likely that these studies must have included CSE-patients who met the criteria of a psychiatric disorder. Comorbid psychopathology in our CSE-patients is quite frequent (36\% at diagnosis, $22 \%$ at follow-up) and psychopathology at diagnosis is a negative prognostic factor for the course of CSE. As there are several evidence-based treatment options for common mental disorders such as anxiety and mood disorders, motivating newly diagnosed CSE patients for psychiatric treatment should be of priority. There is no evidence-based treatment for CSE, but many patients could benefit from treatment of their comorbid psychiatric disorder and improve their quality of life as well as possibly also their neuropsychological prognosis. However, some caution must be taken into account: evidence-based guidelines for common mental disorders are constructed for patients with psychopathology only. In other patient groups with a combination of a somatic disease and a psychiatric disorder psychopharmaceutic treatment or psychotherapies have been shown to be not as effective as for patients without somatic comorbidity (e.g. Kootker et al. 2017; Tedeschini et al. 2011). As half of the patients in this study group need some kind of social security and probably have loss of income (Eshuis 2010), it can be inferred that a part of these patients has decreased social contacts and daily activities, taking into account that the large majority is between 40 and 60 years old. The decrease in purposeful, social and pleasurable activities is a risk factor for psychopathology and could be target of rehabilitation interventions or contextual psychological interventions such as behavioural activation (Richards et al. 2016). As there is only a little evidence base for the treatment options of this CSE-patient group, the intervention choices for the consequences of CSE in daily life will be an educated guess, using scientific data from other patient groups.

Some limitations of this study merit attention. A major limitation is the lack of a control group. This has been partly covered by the use of adequate normative data, but these norm groups differ across neuropsychological tests. An advantage of the different normative data is the spread of control data across norm populations. Another limitation is the retrospective measurement of cumulative exposure, rendering the exposure estimation less reliable, which might explain the lack of significant results related to exposure data. The number of statistical analyses in relation to the number of people in the study group is fairly high. Some significant findings might be due to chance, although effect sizes point in the direction of small-to-medium effects. Whereas more study patients would have been desirable, CSE is a rare disease and we chose to apply stringent diagnostic criteria, further reducing the number of patients within the study group. A limitation of the design of the study is that the diagnosis of CSE at follow-up was not blind. Only one patient was excluded at follow-up because of evidence for a neurodegenerative disease (Parkinson). Blinding of the previous diagnosis of the patients, or diagnosis by another team, could have changed the diagnosis, although for every patient the diagnostic criteria were applied in a protocolled manner. In practice, it was not possible to set up another diagnostic team for the blinding of the diagnosis at follow-up.

This study also has several strengths. In the Netherlands, there is a unique curative infrastructure for the multidisciplinary diagnosis of CSE. The two Solvent Teams are established and rather well-known centres of expertise and patients are referred from all over the country for diagnosis. The diagnosis is made on medical grounds and the Solvent Teams do not have a role in financial compensation procedures. The diagnostic assessment is covered by the mandatory health insurance for the Dutch population. This means that the Solvent Teams have a national coverage of the total number of CSE patients. Furthermore, the protocolled diagnostic procedure is well described and is the same for all included patients. Patients are only selected at time of first diagnosis and are prospectively followed up after diagnosis. The patient selection is well described and only showed differences between lost to follow-up and patient group with respect to involvement in litigation. The study group was less involved in litigation, which decreases the influence of secondary gains on the description of the course of CSE. With respect to the neuropsychological assessment, patients with concerns regarding performance validity are excluded and psychopathology is classified according to DSM-IV criteria. Also, this is the first follow-up study in which all 
previously found predictors are measured and analysed within one patient group.

Future studies would benefit from longer follow-up times, enabling the investigation of whether CSE patients remain relatively stable, although a longer follow-up period in a clinical patient group has the risk of increased loss to followup and the risk of a biased study group selection. A longer follow-up period on the other hand could give more insight if there is a part of the patient group who do progress into dementia or have an exacerbation of age-related cognitive impairment.

Future studies of newly diagnosed patients however will not likely take place in the Netherlands; the number of new CSE cases is declining, due to improved working conditions and outsourcing labour in jobs with high solvent exposure to low and middle-income countries where regulation and hygienic conditions are less stringent. So the problem of adverse health effects of chronic solvent exposure is also outsourced to other countries. It is important that knowledge on the harmful effects of solvent exposure is available in the countries where most of the exposure is nowadays. Preventive measures such as the use of water-based paints and glues and personal protection measures should be of priority to prevent the incidence of CSE globally. The good news is that by substitution and by organizing safe working conditions, CSE is a disease that can be prevented, so action is needed. In countries with diminishing incidences of CSE, vigilance is needed to keep working conditions safe and to prevent new cases of CSE.

\section{Compliance with ethical standards}

Conflict of interest The authors declare that they have no conflict of interest.

Ethical approval As this study concerns care as usual, no extra interventions or medical and psychological assessments are conducted and no special research approval was needed. Therefore, a dispensation decision for this study was obtained from the Medical Ethics Committee of the Academic Medical Center Amsterdam (Amsterdam, Medical Ethics Committee Academic Medical Center number 06.17.1378). All procedures performed in studies involving human participants were in accordance with the ethical standards of the institutional and/or national research committee and with the 1964 Helsinki declaration and its later amendments or comparable ethical standards.

Open Access This article is distributed under the terms of the Creative Commons Attribution 4.0 International License (http://creativeco mmons.org/licenses/by/4.0/), which permits unrestricted use, distribution, and reproduction in any medium, provided you give appropriate credit to the original author(s) and the source, provide a link to the Creative Commons license, and indicate if changes were made.

\section{References}

Åbjörnsson G, Palsson B, Bergendorf U, Karlson B, Österberg K, Seger L, Ørbæk P (1998) Long-term follow-up of psychological distress, social functioning, and coping style in treated and untreated patients with solvent-induced chronic toxic encephalopathy. J Occup Environ Med 40(9):801-807

Aerts L, Heffernan M, Kochan NA, Crawford JD, Draper B, Trollor JN, Sachdev PS, Brodaty H (2017) Effects of MCI subtype and reversion on progression to dementia in a community sample. Neurology 88:2225-2232

Amieva H, Letenneur L, Dartigues JF, Rouch-Leroyer I, Sourgen C, D’Alchée-Birée F, Dib M, Barberger-Gateau P, Orgogozo JM, Fabrigoule C (2004) Annual rate and predictors of conversion to dementia in subjects presenting mild cognitive impairment criteria defined according to a population-based study. Dement Geriatr Cogn Disord 18:87-93

Baker EL, Letz RE (1985) A computer-administered neurobehavioral evaluation system for occupational and environmental epidemiology. J Occup Med 27:206-212

Baker EL, Seppäläinen AM (1986) Human aspects of neurobehavioral effects. Report of the workshop session on clinical and epidemiological topics. Neurotoxicology 7:45-56

Bruhn P, Arlien-Soborg P, Gyldensted C, Christensen EL (1981) Prognosis in chronic toxic encephalopathy. A two-year follow-up study in 26 house painters with occupational encephalopathy. Acta Neurol Scand 64(4):259-272

Bushnell PJ, Kavlock RJ, Crofton KM, Weiss B, Rice DC (2010) Behavioral toxicology in the 21st century: challenges and opportunities for behavioural scientists. Summary of a symposium presented at the annual meeting of the neurobehavioral teratology society. Neurotoxicol Teratol 32:313-328

Canevelli M, Grande G, Lacorte E, Quarchioni E, Cesari M, Mariani C, Bruno G, Vanacore N (2016) Spontaneous reversion of mild cognitive impairment to normal cognition: a systematic review of literature and meta-analysis. J Am Med Dir Assoc 17:943-948

Derogatis LR. SCL-90-R: administration, scoring and procedures manual, 3ed ed. Minneapolis, National Computer Systems, 1975

Deutsche Gesetzliche Unfallversicherung (2007) Polyneuropathy or encephalopathy caused by organic solvents, in isolation or in mixtures. Occupational disease report $2 / 2007$ e occupational disease no. 1317

Dick FD, Bourne VJ, Semple SE, Fox HC, Miller BG, Deary IJ, Whalley LJ (2010) Solvent exposure and cognitive ability at age 67: a follow-up study of the 1947 Scottish Mental Survey. Occup Environ Med 67(6):401-407

Dryson EW, Ogden JA (2000) Organic solvent induced chronic toxic encephalopathy: extent of recovery, and associated factors, following cessation of exposure. Neurotoxicology 21(5):659-65

Edling C, Ekberg K, Ahlborg G, Alexandersson JrR, Barregard L, Ekenvall L, Nilsson L, Svensson BG (1990) Long-term follow up of workers exposed to solvents. Br J Ind Med 47(2):75-82

Eshuis W (2010) Financial damage caused by organic psycho syndrome? Financial situation of OPS victims. [In Dutch. In: Financiële schade door OPS? Onderzoek naar de financiële situatie van slachtoffers van OPS.]. Hugo Sinzheimer Institute, Faculty of Law, University of Amsterdam, Amsterdam

Ettema JHM, Arrindell WA (2003) Symptom Check List-90; Manual for a multidimensional indicator of psychopathology [in Dutch: SCL-90; Handleiding bij een multidimensionele psychopathologie-indicator]. Pearson, Lisse

European Commission (2009) Directorate-general for employment, social affairs and equal opportunities F4 unit. Information notices on occupational diseases: a guide to diagnosis. https:// doi.org/10.2767/3824 (ISBN 978-92-79-11483-0) 
First MB, Gibbon M, Spitzer L, Williams JBW (1996) User guide for structured clinical interview for DSM-IV Axis I disorders. American Psychiatric Association, Washington, DC

Fransman W, van der Laan G, Huy T, Kromhout H (2002) [In Dutch: Evaluatie van de methode voor beoordeling blootstelling door de Solvent Teams.] Evaluation of the method of exposure assessment as used by the Solvent Teams. Tijdschrift voor toegepaste arbowetenschap 15:24-31

Gerstenecker A, Mast B (2014) Mild cognitive impairment: a history and the state of current diagnostic criteria. Int Psychogeriatr 27:1-13

Godderis L, Maertens N, de Gelder V, De Lamper A, De Ruyck K, Vernimmen M, Bulterys S, Moens G, Thierens H, Viaene M (2010) Genetic susceptibility in solvent induced neurobehavioral effects. Neurotox Res 17:268-78

Hamilton M (1959) The assessment of anxiety states by rating. Br J Med Psychol 32:50-55

Hamilton M (1960) A rating scale for depression. J Neurol Neurosur Psychiatry 23:56-62

Heaton RK, Grant I, Matthews CG (1986) Differences in neuropsychological test performance associated with age, education, and sex. In: Grant I, Adams KM (eds) Neuropsychological assessment of neuropsychiatric disorders. Oxford University Press, New York, NY, USA

International Labour Organization (2010) Identification and recognition of occupational diseases: criteria for incorporating diseases in the ILO list of occupational diseases, vol 74. Occupational safety and health series. International Labour Office, Geneva (ISBN 97892-2-123795-2 ISSN 0078-3129, list of occupational diseases, revised)

Keski-Säntti P, Palmu K, Pitkonen M, Liljander S, Partanen JV, Akila R, Sainio M, Holm A (2012) Multimodal event-related potentials in occupational chronic solvent encephalopathy. Neurotoxicology 33:703-709

Kezic S, Calkoen F, Wenker MA, Jacobs JJ, Verberk MM (2006 Aug) Genetic polymorphism of metabolic enzymes modifies the risk of chronic solvent-induced encephalopathy. Toxicol Ind Health 22(7):281-289

Kootker JA, Rasquin SM, Lem FC, van Heugten CM, Fasotti L, Geurts AC (2017) Augmented cognitive behavioral therapy for poststroke depressive symptoms: a randomized controlled trial. Arch Phys Med Rehabil 98(4):687-694

Lindström K, Antti-Poika M, Tola S, Hyytiainen A (1982) Psychological prognosis of diagnosed chronic organic solvent intoxication. Neurobehav Toxicol Teratol 4(5):581-588

Malek-Ahmadi M (2016) Reversion from mild cognitive impairment to normal cognition: a meta-analysis. Alzheimer Dis Assoc Disord 30:324-330

Morrow LA, Ryan CM, Hodgson MJ, Robin N (1991) Risk factors associated with persistence of neuropsychological deficits in persons with organic solvent exposure. J Nerv Ment Dis 179(9):540-545

Mulder JL, Dekker R, Dekker PH (1996) Dutch adaptation of the California verbal learning test; manual [in Dutch: Verbale Leer en Geheugen Test]. Swets \& Zeitlinger, Lisse

Nordling Nilson L, Sällsten G, Hagberg S, Bäckman L, Barregård L (2002) Influence of solvent exposure and aging on cognitive functioning: an 18 year follow-up of formerly exposed floor layers and their controls. Occup Environ Med 59:49-57

Nordling Nilson LN, Bäckman L, Sällsten G, Hagberg S, Barregård L (2003) Dose-related cognitive deficits among floor layers with previous heavy exposure to solvents. Arch Environ Health 58:208-217

Nordling Nilson L, Barregård L, Sällsten G, Hagberg S (2007) Selfreported symptoms and their effects on cognitive functioning in workers with past exposure to solvent-based glues: an 18-year follow-up. Int Arch Occup Environ Health 81:69-79

Nordling Nilson L, Karlson B, Nise G, Malmberg B, Ørbæk P (2010) Delayed manifestations of CNS effects in formerly exposed printers-a 20-year follow-up. Neurotoxicol Teratol 32:620-626

Ørbæk P, Lindgren M (1988) Prospective clinical and psychometric investigation of patients with chronic toxic encephalopathy induced by solvents. Scand J Work Environ Health 14(1):37-44

Petersen RC (2016) Mild cognitive impairment. Continuum 22:404-418

Richards DA, Rhodes S, Ekers D, McMillan D, Taylor RS, Byford S, Barrett B, Finning K, Ganguli P, Warren F, Farrand P, Gilbody S, Kuyken W, O'Mahen H, Watkins E, Wright K, Reed N, Fletcher E, Hollon SD, Moore L, Backhouse A, Farrow C, Garry J, Kemp D, Plummer F, Warner F, Woodhouse R (2017) Cost and Outcome of BehaviouRal Activation (COBRA): a randomised controlled trial of behavioural activation versus cognitive-behavioural therapy for depression. Health Technol Assess 21(46):1-366

Ridgway P, Nixon TE, Leach JP (2003) Occupational exposure to organic solvents and long-term nervous system damage detectable by brain imaging, neurophysiology or histopathology. Food Chem Toxicol 41:153-187

Sabbath EL, Gutierrez LA, Okechukwu CA, Singh-Manoux A, Amieva H, Goldberg M, Zins M, Berr C (2014) Time may not fully attenuate solvent-associated cognitive deficits in highly exposed workers. Neurology 82(19):1716-1723

Sainio MA (2015) Neurotoxicity of solvents. In: Lotti M, Bleecker ML (eds) Handbook of clinical neurology, vol 131. Elsevier, Amsterdam, pp 93-110

Schmand B, de Sterke S, Lindeboom J (1999) The Amsterdam shortterm memory test, manual. Swets and Zeitlinger, Lisse

Schmand B, Houx P, de Koning I (2012) The Stroop Colour Word test, the Trail Making test, the Rivermead Behavioural Memory test, Verbal fluency test. Dutch norms. Netherlands Institute of Psychologists, Section of Neuropsychology, Amsterdam

Schmand B, Rienstra A, Tamminga H, Richard E, van Gool WA, Caan MW (2014) Majoie CB responsiveness of magnetic resonance imaging and neuropsychological assessment in memory clinic patients. J Alzheimers Dis 40:409-418

Stern Y (2002) What is cognitive reserve? Theory and research application of the reserve concept. J Int Neuropsychol Soc 8:448-460

Tang CY, Carpenter DM, Eaves EL, Ng J, Ganeshalingam N, Weisel C, Qian H, Lange G, Fiedler NL (2011) Occupational solvent exposure and brain function: an fMRI study. Environ Health Perspect 119:908-913

Tedeschini E, Levkovitz Y, Iovieno N, Ameral VE, Nelson JC, Papakostas GI (2011) Efficacy of antidepressants for late-life depression: a meta-analysis and meta-regression of placebo-controlled randomized trials. J Clin Psychiatry 72:1660-1668

Tombaugh TM (1996) TOMM test of memory malingering, manual. Multi Health Systems, Toronto

van Thriel C (2015) Toxicology of solvents (including alcohol). In: Reference module in biomedical research, 3rd edn. https://doi. org/10.1016/B978-0-12-801238-3.00210-5

van Groenestijn MAC, Akkerhuis GW, Kupka RW, Schneider N, Nolen W (1999) Structured clinical interview for DSM-IV Axis I disorders [in Dutch: Gestructureerd Klinisch Interview voor de vaststelling van DSM-IV As I Stoornissen]. Swets Test Publishers, Lisse

van Hout MSE, Schmand B, Wekkin EM, Hageman G, Deelman BG (2003) Suboptimal performance on neuropsychological tests in patients with suspected chronic toxic encephalopathy. Neurotoxicology 24:547-551

van Hout MSE, Wekking EM, Berg IJ, Deelman BG (2008) Psychosocial and cognitive rehabilitation of patients with solvent-induced 
chronic toxic encephalopathy: a randomised controlled study. Psychother Psychosom 77:289-297

van Valen E, Wekking E, van der Laan G, Sprangers M, van Dijk F (2009) The course of chronic solvent induced encephalopathy: a systematic review. Neurotoxicology 30:1172-1186

van Valen E, van Thriel C, Akila R, Nilson LN, Bast-Pettersen R, Sainio M, van Dijk F, van der Laan G, Verberk M, Wekking E (2012) Chronic solvent-induced encephalopathy: European consensus of neuropsychological characteristics, assessment, and guidelines for diagnostics. Neurotoxicology 33:710-276

van Valen E, van Hout MSE, Wekking EM, Lenderink AL, van der Laan G, Hageman G (2015) Brain damage caused by exposure to organic solvents; diagnostics and disease course of chronic solvent-induced encephalopathy. Ned Tijdschr Geneeskd 159:A9431

van der Laan G, van Dun R, Roos Y, Huy T, Wekking E, Hooisma J, Kulig B, Emmen H, Monster A, de Wolf F (1995) [In Dutch: "Organisch Psycho Syndroom door oplosmiddelen? Een protocol voor de diagnostiek] Organic Psycho Syndrome caused by solvents? A protocol for diagnosis. Dutch Ministry of Social Affairs and Employment, SWZ S186

Verhage F (1964) Intelligence and age (in Dutch). Van Gorcum, Assen

Visser RSH (1970) On the copying of the Rey complex figure; a neuropsychological study [in Dutch: Over het natekenen van de complexe figuur van Rey, een neuropsychologisch onderzoek]. Thesis, Swets en Zeitlinger, Amsterdam

Visser I, Lavini C, Booij J, Reneman L, Majoie C, de Boer AG, Wekking EM, de Joode EA, van der Laan G, van Dijk FJ, Schene AH, Den Heeten GJ (2008) Cerebral impairment in solvent-induced encephalopathy. Ann Neurol 63:572-580

Warrington EK (1984) Recognition memory test: manual. NFERNelson, Windsor

Wechsler D (1981) Wechsler adult intelligence scale-revised: manual. The Psychological Corporation, Cleveland

Wechsler D (1987) Wechsler memory scale-revised. The Psychological Corporation, San Antonio

Wechsler D (2001) Wechsler adult intelligence scale-III: manual (Dutch version). Swets \& Zeitlinger, Lisse

Wechsler D (2004) Wechsler adult intelligence scale, third edition: [In Dutch: Nederlandstalige bewerking afname en scoringshandleiding]. Harcourt Test Publishers, Amsterdam

White RF, Proctor SP (1997) Solvents and neurotoxicity. Lancet 349:1239-1243

World Health Organization (WHO) (1985) Chronic effects of organic solvents on the central nervous system and diagnostic criteria, vol 5. Environmental health. WHO, Copenhagen 